\title{
Guideline Principles for Designing Astronomy Activities
}

\author{
Linda Strubbe \\ Canadian Institute for Theoretical Astrophysics \\ email: linda@cita.utoronto.ca
}

\section{Introduction}

We astronomy outreachers are passionate about sharing astronomy widely-but many astronomy outreach activities are designed more by how we hope things will work than in a careful intentional way. We also rarely evaluate how well our activities are achieving our goals. As a result, many educational activities must be significantly less effective than they could be. Fortunately, there is a large body of education research on how people learn. If we are serious about sharing astronomy widely and effectively, we must treat our teaching like research: (1) Have clear goals for our outreach, evaluate how well we are achieving our goals, and revise our strategies in light of what we learn; and (2) Use appropriate teaching techniques supported by education research wherever possible.

I have summarized a few top teaching principles from education research to help design effective astronomy activities. A more detailed 2-page version is available at: http://www. cita. utoronto.ca/Ĩinda/eduresearch.pdf.

(a) Be strongly goal-oriented in designing and evaluating activities:

(a) Clearly state your goals for your learners (see below).

(b) Determine what evidence would tell you your learners are reaching your goals.

(c) Design your activity to help your learners achieve these goals.

(d) During / after the activity, evaluate how well learners have achieved your goals.

(e) Use what you learned about your students to revise the activity, for the future.

(b) Choose your learning goals carefully:

Three different important types of goals concern:

(a) Scientific content - What do we want to students to know/understand?

(b) Scientific process skills — What do we want students to be able to do?

(c) Scientific attitudes - How do we want students to feel about science / education in general / life?

\section{References}

Chinn C. A. \& Malhotra, B. A. 2002, Epistemologically Authentic Inquiry in Schools: A Theoretical Framework for Evaluating Inquiry Tasks, Science Education, 86, 175

National Research Council (NRC) 2000, How People Learn: Brain, Mind, Experience, and School. (Washington, DC: The National Academies Press).

National Research Council (NRC) 2007, "Chapter 2: Four Strands of Science Learning." Ready, Set, SCIENCE!: Putting Research to Work in K-8 Science Classrooms. (Washington, DC: The National Academies Press).

Wiggins, G. \& McTighe, J. 2005, Understanding by Design. (Alexandria: Association for Supervision and Curriculum Development). 